\title{
O SANTUÁRIO DE SANTA PAULINA EM NOVA TRENTO (SANTA CATARINA - BRASIL): FORMAS SIMBÓLICAS E INSTITUCIONALIDADE DO CARISMA DE AMABILE LÚCIA VISINTAINER
}

\section{The Shrine of Santa Paulina in Nova Trento (Santa Catarina- Brazil): symbolic forms and institucionality of the Amabile Lúcia Visintainer's charisma}

\author{
Ana Helena Corrêa de Freitas Gil ${ }^{1}$ \\ Sylvio Fausto Gil Filho ${ }^{2}$
}

\begin{abstract}
RESUMO
O presente artigo visa uma análise do santuário católico romano dedicado a Santa Paulina em Nova Trento (SC) no Brasil, baseado em uma Geografia da Religião inspirada na releitura da teoria das formas simbólicas de Ernst Cassirer. A partir dessa fundamentação teórica articulada às espacialidades, engendradas pela religião como forma simbólica e estrutura edificante da realidade, interpretamos o Santuário católico de Santa Paulina no que se refere ao homem religioso. Contudo, os santuários católicos são espaços de estruturas hierofânicas onde as experiências religiosas dos peregrinos são projetadas em representações e devidamente apropriadas no discurso religioso institucional. Desse modo, a apropriação do carisma de Amabile Lúcia Visintainer marca a territorialidade da instituição Igreja e as espacialidades de expressões e de representações dos peregrinos.
\end{abstract}

Palavras-chave: Santa Paulina; formas simbólicas; carisma; territorialidade católica.

\begin{abstract}
The present paper aims at analysing the Catholic Roman dedicated shrine Santa Paulina in Nova Trento (SC) in Brazil based in a Geography of Religion inspired in the special interpretation about Ernst Cassirer's symbolic forms theory. Starting from that articulated theoretical fundamentation of the spacialities engendered by the religion as a symbolic form and structuring structure of reality Santa Paulina's Catholic Shrine is interpreted concerning the religious man. However, the Catholic shrines are spaces of hierophanic structures where the pilgrims' religious experiences are projected in representations and properly appropriate in the institutional religious discourse. This way, the appropriation of the charisma of Amabile Lúcia Visintainer establishes the territoriality of the institutional Church and the spatiality of expressions and representations of the pilgrims.
\end{abstract}

Keywords: Santa Paulina; symbolic forms; charisma; catholic territoriality.

1 Professora do Instituto Federal do Paraná, mestre e doutoranda do Programa de Pós-Graduação em Geografia da UFPR na linha de pesquisa Território, Cultura e Representação. Correio eletrônico: anahgil@ufpr.br.

2 Professor Adjunto Doutor do Departamento de Geografia da Universidade Federal do Paraná, Pesquisador do Núcleo Paranaense de Pesquisa em Religião (NUPPER) e do Núcleo de Estudos em Espaço e Representações (NEER). Correio eletrônico: faustogil@creapr. org.br. 
GIL, A. H. C. F.; GIL FILHO, S. F. O santuário de Santa Paulina em Nova Trento...

\section{INTRODUÇÃO}

A cidade de Nova Trento (SC) $)^{3}$, a partir do processo de institucionalização do carisma de Amabile Lúcia Visintainer - Madre Paulina, é dotada de sentido religioso em um sistema de trocas simbólicas que reestruturam o cotidiano local. Como lembra Eliade $(1995)^{4}$ "nunca será demais insistir neste paradoxo que constitui a hierofania, até mais elementar." A manifestação do sagrado torna qualquer coisa em outra coisa, qualquer ser em outro ser; encontra uma ordem distinta em toda relação com o mundo. Fundamentalmente, as coisas ditas sagradas são outras, muito embora permaneçam as mesmas.

O aporte teórico parte do pressuposto que o homem é mais que um ser cultural, ele é simbólico. Desse modo, o homem produz símbolos e estes o caracterizam como superação da vida biológica. Há, assim, uma ruptura da ordem natural criada pelo homem e à qual ele deve se submeter. Esse processo insere o homem em um universo simbólico. Assim, a religião e o mito são formas simbólicas desse universo pleno de significados, que faz parte indissociável de espacialidades de percepções e expressões, representações e do próprio pensamento religioso.(GIL FILHO, 2007) . $^{2}$

Por outro lado, a ação da Instituição religiosa se expressa nas limitações imperativas do controle e gestão de determinado espaço sagrado, onde há uma restrição objetiva galvanizada em representações simbólicas apropriadas de determinado carisma. Sendo sua materialidade imediata o próprio território sagrado institucionalizado sob forma de santuário.

$\mathrm{Na}$ biografia de Amabile Lúcia registrada por Guido Lorenzi (2001, p. 38) “ La Beata Madre Paolina - fra carisma e obbedienza" originalmente publicado em $1991^{6}$ em uma obra de cunho estritamente religioso, descreve a representação da inspiração religiosa de Amabile através de um sonho com a Virgem de Lourdes, a qual havia dito:
Desejo ardentemente que comeces uma obra para a salvação (santificação) das minhas filhas." Ela respondeu: "Que poderei fazer sou tão pobre e ignorante?" Não houve resposta na hora, mas à noite de outro dia, a Virgem aparece e pergunta: "Filha querida, que decidiste?" Amabile respondeu "Minha Mãe, meu único desejo é servir-vos, mas sou uma pessoa pobre. "A Virgem se aproximou e disse: "Dar-te-ei alguém que te ajudará neste trabalho. (LORENZI, 2001, p. 38)

Segundo a narrativa uma pessoa, o jesuíta Marcello Rocchi (1887), chega a Nova Trento e descobre em Amabile o carisma religioso.

O carisma agora, pouco a pouco, passa a ser catalisado pela Igreja que posteriormente segue em várias etapas de sua institucionalização: (i) inicialmente na forma do serviço religioso e vocação religiosa do plano da cultura católica; (ii) depois no ideal do sacrifício cristão, necessário à santificação; (iii) a formação da Congregação das Irmãzinhas da Imaculada Conceição e (iv) finalmente no referendo do culto autorizado e legitimado no processo de canonização. Desse modo, a espacialidade das representações é articulada ao discurso religioso fundador que remete à transcendência inicial consubstanciada no carisma.

O carisma que inicialmente aparece como um dom divino é posteriormente operacionalizado no discurso religioso católico onde é estabelecida "uma ordem objetiva e funcional”. (GHISLANDI, 2008, p. 26). ${ }^{7}$ O Santuário é a expressão concreta de intencionalidades geradas a partir da direção institucional, uma síntese de espacialidades onde operam as formas religiosas. A apropriação do carisma reveste-se em uma forma de territorialidade católica na medida em que as relações de poder estabelecem uma associação institucional, que produz marcas na paisagem de ordem monumental determinando limites de gestão da Igreja em determinadas representações.

3 Nova Trento situa-se no Vale do Rio Tijucas, próxima 84 km de Florianópolis, Brusque, 21 km ao Norte e, a Nordeste, Balneário Camboriú, a $60 \mathrm{~km}$ e Tijucas a $31 \mathrm{~km}$. Situa-se a $27^{\circ} 17^{\prime} 09^{\prime}$ de latitude sul e $48^{\circ} 5517^{\prime}$ de longitude oeste. O município possui três distritos: Distrito Sede, Distritos de Aguti e Claraíba. A população, censo de 2000, é de 9.853 habitantes, sendo $63 \%$ urbana e $37 \%$ rural.

4 ELIADE, M. O Sagrado e o Profano: A Essência das Religiões. São Paulo: Martins Fontes, 1995.

5 GIL FILHO, S. F. Geografia da Religião: Reconstruções Teóricas sob o Idealismo Crítico. In: KOZEL, S.; SILVA, J. C.; GIL FILHO, S. F. Da Percepção e Cognição à Representação: Reconstruções Teóricas da Geografia Cultural e Humanista. São Paulo: Terceira Margem, 2007.

6 LORENZI, G. Madre Paulina entre carisma e obediência. São Paulo: Edições Loyola, 2001. p. 38.

7 GHISLANDI, M. A. Entre carisma e Poder: o Território e Territorialidades da Ordem Capuchinha em Curitiba a partir de São Francisco de Assis. Dissertação (Mestrado em Geografia) - Programa de pós-graduação em Geografia - Setor de Ciências da Terra, Universidade Federal do Paraná, Curitiba, 2008. p. 26. 
GIL, A. H. C. F.; GIL FILHO, S. F. O santuário de Santa Paulina em Nova Trento...

\section{AMABILE LÚCIA VISINTAINER NO BRASIL: PROCESSO DE REPRODUÇÃO DAS REPRESENTAÇÕES RELIGIOSAS}

Amabile Lúcia Visintainer nasceu no dia 16 de dezembro de 1865, filha de Antonio Visintainer e Anna Pianezzer, ambos camponeses da região de Trento em Vígolo Vattare. Foi a segunda filha do casal que teve ao todo 14 filhos. De família pobre, de educação eminentemente católica, Amabile foi batizada logo no dia seguinte ao seu nascimento. Depois de dez anos, seus pais resolveram emigrar para o Brasil, devido às incertezas econômicas e difíceis condições de vida da Europa, onde havia problemas de pragas que prejudicavam o cultivo das videiras e a criação do bicho-daseda, principais fontes de renda da população da região tridentina.

Projeta-se as representações de santidade no discurso dos biógrafos sobre a infância difícil devido à pobreza, à resignação diante do sofrimento e manifestação de qualidades espirituais inatas.

Antes de vir ao Brasil, Amabile cuidara de sua avó doente como uma enfermeira, que em seu leito lhe deu uma bênção particular Ihe dizendo: "Como foste generosa e doce comigo, tu o serás com tantos outros no mundo novo aonde irás; muitos te recordarão, como eu, com gratidão e amor." (CADORIN, 2001, p. 21) Nesse ponto a narrativa introduz o marco carismático na biografia de Amabile como um senso de missão divinamente escolhido. É justamente na operação da forma simbólica da linguagem que os significados das expressões míticas e religiosas são resignificados. A narrativa nos conduz a outro mundo fora da crueza da materialidade imediata da vida e nos transporta para um universo simbólico de significados próprios da doutrina católica romana, onde há uma articulação tácita do plano institucional do que se entende por santidade. Além da prática espiritual das virtudes do ser histórico está a interpretação legitimada que faz a conformação simbólica autorizada da realidade religiosa.

A emigração italiana da segunda metade do século XIX é caracterizada por alguns grupos de tiroleses que foram atraídos pelo Contrato Caetano Pinto no incentivo de emigrantes para o Brasil para trabalho no campo. A família Visintainer inicialmente se estabelece próximo a Itajaí e Brusque, em Santa Catarina, especificamente na localidade de Alferes, no vale do rio Tijucas, local que foi denominado mais tarde de "Nova Trento", uma alusão à terra deixada na Itália, a Trento de São Virgílio.

Em dezembro de 1879, os jesuítas estabelecem uma residência dedicada ao "Sagrado Coração de Jesus" com três sacerdotes vindos da Itália, que marca o processo de estruturação de diversas práticas católicas, em especial a novena de Natal que funciona como base da consciência religiosa que entre os imigrantes alude à terra de onde saíram e a necessária justificação de base espiritual na adaptação à nova terra.

O processo de construção das representações religiosas a partir da ideia do carisma ${ }^{9}$, no âmbito do Catolicismo Romano, paulatinamente afasta-se do conceito de "dom" e torna-se um "sentido" construído no plano do discurso. De modo correlato o discurso religioso desloca e canaliza o poder carismático estruturante em uma estrutura estruturada na qual legitima-se. Os mundos das expressões em um espaço de práticas subsumam-se em um mundo de representações religiosas legitimadas. A Igreja interpreta o carisma como dom divino sempre a serviço da instituição. O próprio catecismo oficial da Igreja sugere esta interpretação: "Sejam extraordinários e, sejam simples e humildes, os carismas são graças do Espírito Santo que, direta ou indiretamente, têm uma utilidade eclesial, ordenados que são à edificação da Igreja, ao bem dos homens e às necessidades do mundo". ${ }^{10}$ Ou seja, a apropriação do carisma é simétrica à realização do poder religioso e sua práxis.

Sendo o carisma conjuntivo às relações de poder ele funciona como um elemento do esquema simbólico da religião em sua função de engendrar a realidade e assim também como parte estruturante da territorialidade católica.

\section{AMÁBILE: SINAL DA TERRITORIALIDADE JESUÍTA EM NOVA TRENTO}

Religiosos da Companhia de Jesus se fazem presentes em Nova Trento a partir de 1879. As práticas

8 CADORIN, C. B. Ser para os outros - perfil biográfico de madre Paulina do Coração Agonizante de Jesus Amabile Visintainer 1865-1942. São Paulo: Loyola, 2001, p. 21.

9 A etimologia da palavra carisma vem do étimo inicial háris do grego, que significa graça. Como derivativos temos a palavra hárisma, harísmatos, que formou o atual termo em português que perpassa o latim clássico chárisma, charísmatis, como sendo"dom da natureza", utilizado em São Jerônimo. Hodiernamente a palavra transfere-se para o campo político social como talento da liderança política, ou uma unção demagógica de chefia social. 199. p. 198.

10 IGREJA CATÓLICA ROMANA. Catecismo da Igreja Católica. Petrópolis: Editora Vozes, Paulinas, Loyola e Ave-Maria. 1993, § 
GIL, A. H. C. F.; GIL FILHO, S. F. O santuário de Santa Paulina em Nova Trento...

jesuítas produzem marca na territorialidade católica que acompanham a própria história de Nova Trento, que, quanto à sua emancipação enquanto município em 1892, tinha a presença de três congregações religiosas sendo duas masculinas (os próprios jesuítas e os "Irmãos da Congregação do Santíssimo Coração de Jesus") além de uma feminina, a "Congregação das Irmãzinhas da Imaculada Conceição", fundada por Amábile Lúcia Visintainer e Virgínia Rosa Nicolodi que foi reconhecida em 27 de outubro de 1947 pelo Papa Pio XII.

Afora esse universo dos fatos, aflora, na narrativa autorizativa de Lorenzi, o surgimento da Nova Congregação no contexto do sentido religioso circunscrito ao carisma de Amabile, que junto com Virgínia cuidam de uma senhora com câncer cujos parentes não tinham condições de amparar e assim através do sacerdote (o padre jesuíta Marcello Rocchi), iniciam em uma casa de madeira uma enfermaria. A forma simbólica da religião plasma assim o lugar manifesto como um espaço de ação do cuidar onde a piedade religiosa se realiza.

Em 1894 é consagrado bispo Dom José de Camargo Barros, que conhecia o padre Rocchi, e que lhe pede para visitar Nova Trento e conhecer o trabalho realizado pelas "Irmãzinhas". Deste modo, Amabile pede ao bispo a autorização para o grupo voluntário como uma regular Comunidade Religiosa, o que foi autorizado, tendo como responsável pela nova Congregação o padre Rocchi, que deveria também preparar as "irmãs" para a escolha do hábito e das regras e para receber os votos das três "irmãs", Amabile, Virgínia e Teresa. Assim se consubstancia a intervenção jesuíta em um processo de institucionalização da prática religiosa na qual o espaço das práticas conformado pela religião é apropriado e transformado em territorialidade católica.

A territorialidade católica jesuíta se realiza no contexto camponês de Nova Trento do final do século XIX onde o espaço da prática cotidiana subsome-se às estruturas de poder religiosas católicas. De certo modo, o rito disciplina a conformação do cotidiano externo ao controle religioso transformando o contexto cultural onde a vida exclusivamente religiosa torna-se viável.

A consagração à vida religiosa com as disciplinas dos valores da castidade, obediência e pobreza são parte da conformação dos sentidos simbólicos religiosos em que o discernimento da sacralidade é representa- do. Essas representações são temporo-espacialmente realizadas nas práticas religiosas e nas estruturas por elas animadas. Desse modo as motivações religiosas se expressam em um espaço de ação que dialeticamente retorna enquanto consciência religiosa sintetizada na comunidade e na organização religiosa.

Assim, nessa organização religiosa as representações simbólicas estão tanto na indumentária do hábito com uma túnica preta imitando a dos filhos de Santo Inácio, na cintura uma faixa celeste com cinto, para recordar a consagração a Maria, e o nome da Congregação como "Filhas da Imaculada Conceição". As três irmãs recebem diante do altar os nomes religiosos de Irmã Paulina do Coração Agonizante de Jesus (Amabile Lúcia Visintainer), Irmã Matilde da Imaculada Conceição (Virgínia Rosa Nicolodi) e a Irmã Inês de São José (Teresa Maule). A Congregação, assim tem uma nova semântica fundamentada nas personagens da Sagrada Família com os nomes de Jesus, Maria e José.

A Constituição e Diretórios de 1997 designam a sustentação carismática da Congregação ${ }^{11}$ como "sensibilidade para receber os clamores da realidade e disponibilidade para servir aos mais necessitados e aos que estão em situação de maior injustiça".

Depois de fundar a Congregação e exercer o poder por seis anos Madre Paulina é destituída do cargo sentenciado, posteriormente, com a seguinte declaração do Arcebispo Dom Duarte em 1908: "A Madre Paulina nunca mais exerça nenhum cargo de governo: viva e morra na Congregação como súdita." (CADORIN, $2001)^{12}$. Logo, em 1909, outra Superiora Geral é eleita sendo que as irmãs da congregação são proibidas de votar em Madre Paulina. O relato descrito a partir de documentos da História da Congregação tece algumas referências sobre uma intriga interna, que possibilita a interpretação que houve uma intervenção do clero superior em relação à Congregação. Até 1918 Madre Paulina trabalhou como religiosa, em torno de nove anos, na Santa Casa de Misericórdia e outros oito anos no Asilo São Vicente, em Bragança Paulista. O relato desloca o sentido inicial das relações de poder institucionais para mostrar a resignação de Madre Paulina e torna essa parte da sua biografia também um símbolo de santidade pautado na obediência, que de certo modo é reapropriado no processo de canonização de 2002.

A partir de 1918, com seus 53 anos de idade,

11 CONGREGAÇÃO DAS IRMÃZINHAS DA IMACULADA CONCEIÇÃO. Constituições e Diretório. São Paulo: Casa Geral, 1997. p. $110-111$.

12 CANDORIN, C. B. Ser para os outros - perfil biográfico de Madre Paulina do Coração Agonizante de Jesus Amabile Visintainer1865-1942. São Paulo: Loyola, 2001, p. 81. 
Madre Paulina passa a ter uma vida de caráter monástico, dedicando-se à oração e à contemplação. Seus problemas de saúde já davam sinais, causados pela diabetes, até o extremo da amputação do braço direito, posteriormente perdendo também a visão e em seguida falece no dia 9 de julho de 1942.

\section{A INSTITUCIONALIZAÇÃO DE UM CARISMA}

Em 18 de outubro de 1991, Madre Paulina foi beatificada pelo Papa João Paulo II, quando de sua visita a Florianópolis. Em 19 de maio de 2002, pelo mesmo Papa, em cerimônia pública em Roma, Itália, foi canonizada recebendo oficialmente o nome de "Santa Paulina do Coração Agonizante de Jesus".

O processo de beatificação refere-se ao reconhecimento institucional da Igreja de que a pessoa está em uma condição paradisíaca e, desse modo, pode interceder pelos outros. Na prática há uma autorização para que os fiéis solicitem por meio da prece esta intercessão. A canonização diz respeito à atribuição do grau de Santo a alguém que já era Beato. O processo de canonização, hodiernamente, é a reafirmação do poder da Igreja e parte da sua política em seu afã de evangelização através de referências carismáticas locais.

Os trabalhos pela canonização de Madre Paulina iniciaram-se propriamente em 1965, vinte e três anos após sua morte. O primeiro milagre que lhe foi atribuído aconteceu em 1966, com a cura de uma mulher com hemorragia pós-parto, reconhecido oficialmente em
1989. O caso foi examinado por peritos médicos legais da Congregação Médica da mesma Congregação para as Causas dos Santos. A cura fora atribuída a Madre Paulina do Coração Agonizante de Jesus. A Madre foi invocada com orações feitas publicamente pelos familiares e pelas Irmãs Enfermeiras, Irmãzinhas da Imaculada Conceição que trabalhavam no Hospital e Maternidade de São Camilo da cidade de Imbituba - SC. O segundo milagre, em 1992, refere-se quando uma menina, chamada Ilza Bruna Vieira de Souza, com um tumor cerebral, já desenganada pelos médicos, foi curada, atribuída a intercessão de Madre Paulina.

A condição de intercessão reconhecida pela Igreja em relação a Madre Paulina possibilita a formação do santuário em sua representação monumental. O templo proeminente é expressão material das representações religiosas que compõem junto com outros elementos da paisagem uma composição destinada à peregrinação católica.

\section{A IGREJA DE VÍGOLO E O SANTUÁRIO}

No período de 1876 a 1879, foi construído na região de Vígolo em Nova Trento a Capela de São Jorge. Os responsáveis pela obra foram os moradores da região incentivados pelo padre Marcello Rochi e devido à devoção do sacerdote a Nossa Senhora de Lourdes, o santuário foi dedicado a ela. No ano de 1888, chegou da França a imagem da Virgem de Lourdes, que ficou na Igreja até o dia 11 de fevereiro de 1889.

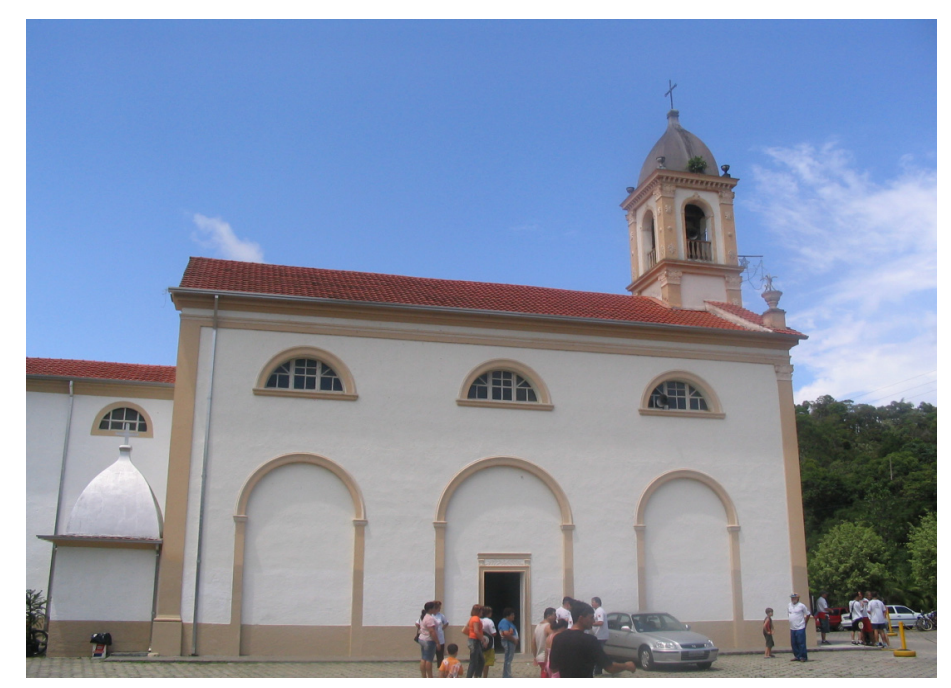

FIGURA 1 - IGREJA DE VÍGOLO CONSTITUÍDO COMO SANTUÁRIO A MADRE PAULINA EM 1998 (NOVA TRENTO/SC)

FONTE: GIL, A. H. C. F. (2005)/Acervo Pessoal 
Em 19 de outubro do ano de 1991, após a beatificação de Madre Paulina, foi colocada a imagem da beata no santuário, e o lugar passa a receber muitos fiéis que chegavam com os atos de fé e devoção principalmente relacionados a cura. O Arcebispo de Florianópolis, Dom Eusébio Oscar Scheid, em 09 de julho de 1998, tornou público a Igreja de Vígolo como Santuário de Madre Paulina. (Figura 1)

Em 2005 um novo Santuário (Figura 2) foi construído, o monumento com 6,9 mil metros quadrados de área coberta e 42 metros no ponto mais alto forma o prédio do templo. Com capacidade para cerca de 3 mil pessoas em um anfiteatro com o altar de granito no centro, sob um pé-direito de 28 metros. O Santuário de característica monumental, em uma topografia elevada simboliza a aspiração vertical própria da transcendência religiosa e ao mesmo tempo que expressa poder religioso exercido pela instituição com a proeminência de suas marcas na paisagem; assim como o próprio complexo é também uma estrutura da territorialidade católica no Brasil.

A constituição do Santuário implica no movimento de um espaço de ação religioso dos fiéis, onde podemos perceber três espacialidades sob a forma simbólica de religião integrada em uma totalidade estrutural.

A espacialidade de expressão e percepção que se realiza nos anseios do peregrino em sua devoção onde o movimento de sua prática religiosa visa a solução de seus problemas cotidianos de ordem material e espiritual. No âmbito do contato social com aqueles que participam das mesmas representações do divino e que em determinado tempo e espaço sagrado realizam atos de transcendência em um novo ponto de equilíbrio da vida cotidiana.

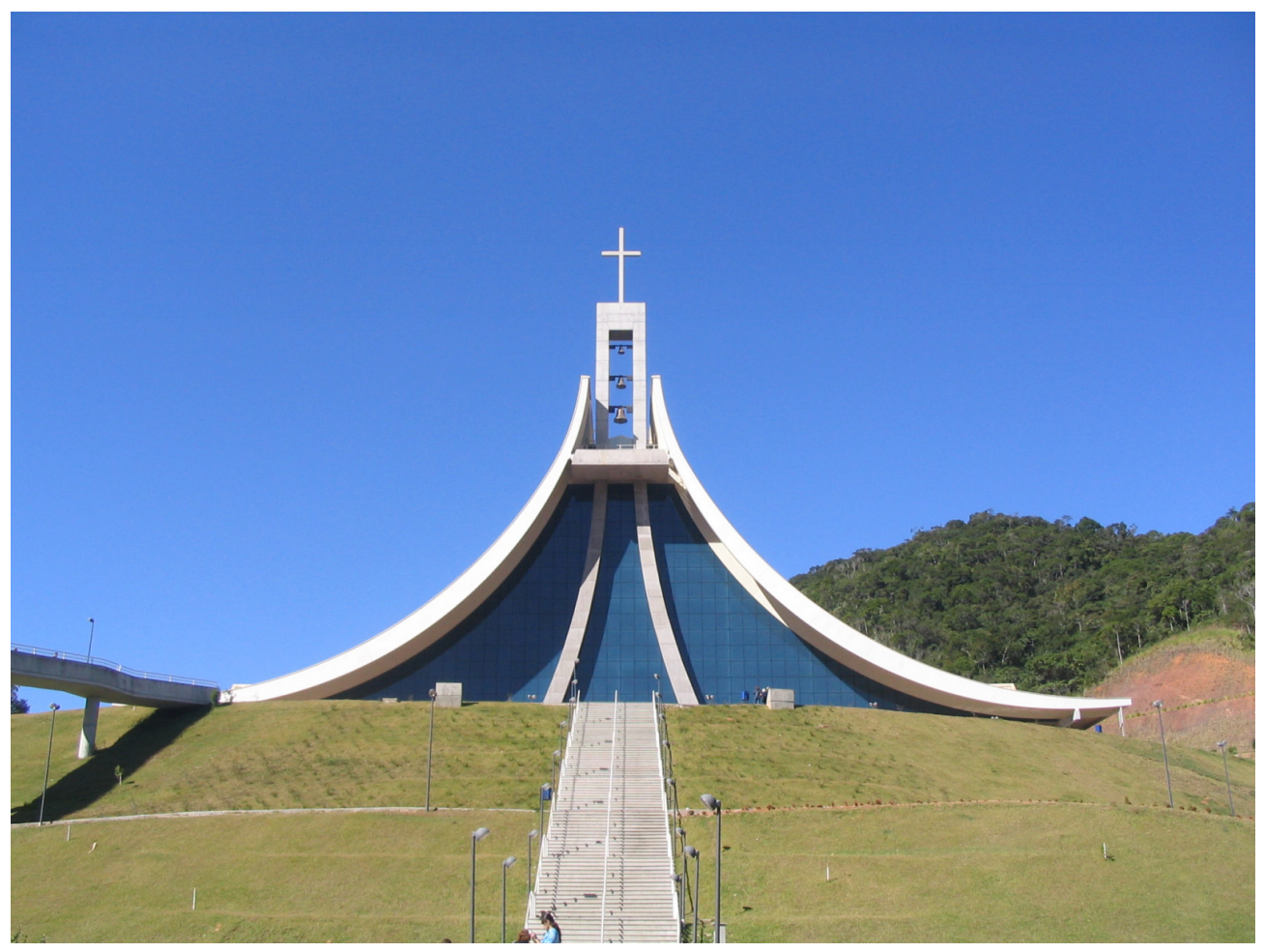

FIGURA 2 - SANTUÁRIO DE SANTA PAULINA DEDICADO POR DOM MURILO SEBASTIÃO RAMOS KRIGER (ARCEBISPO DA ARQUIDIOCESE DE FLORIANÓPOLIS/SC EM 22/01/2006)

FONTE: GIL, A. H. C. F. (2007)/Acervo Pessoal 


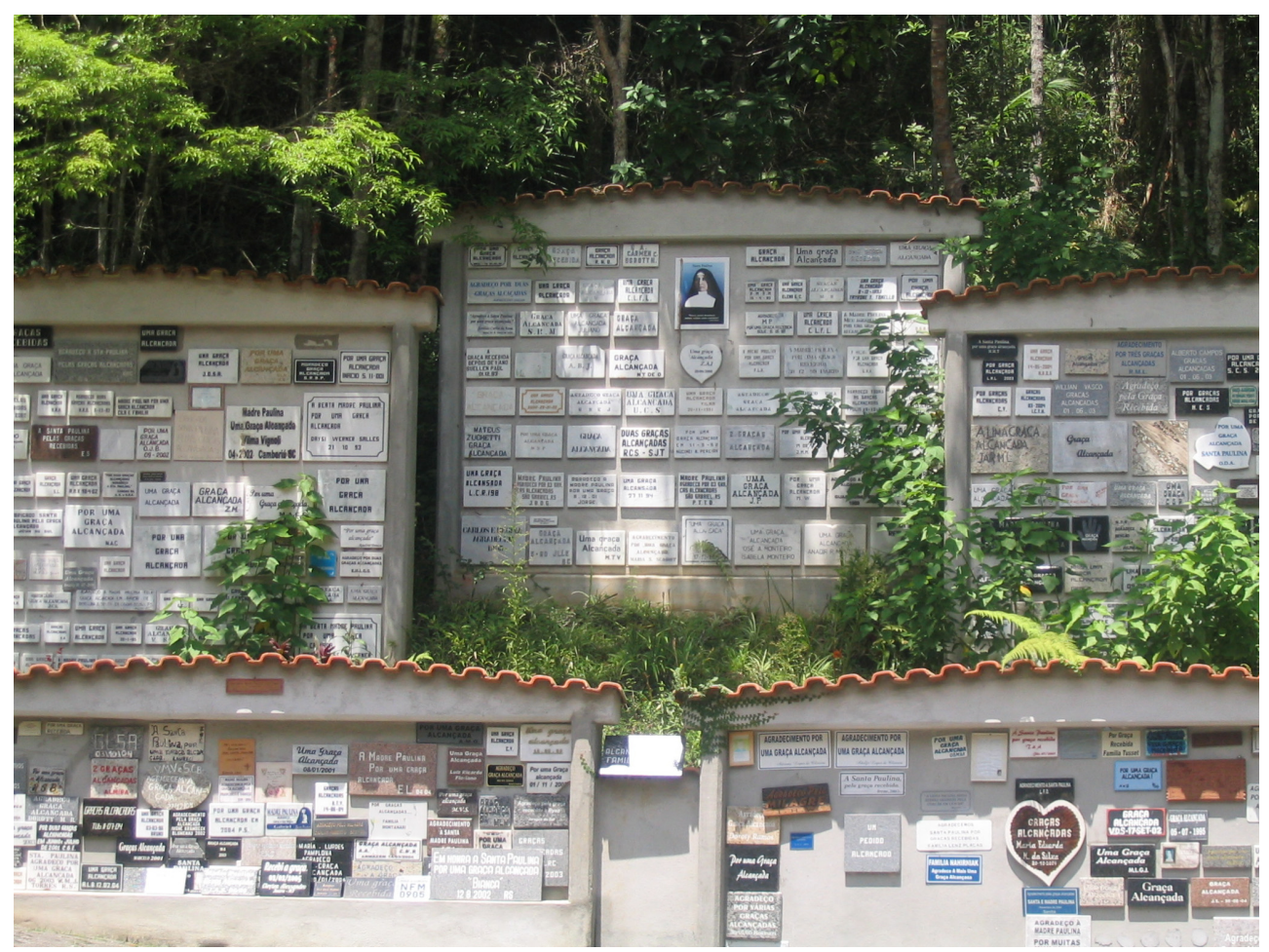

FIGURA 3 - REGISTROS DE GRATIDÃO EM FRENTE À “SALA DOS MILAGRES” NO COMPLEXO DO SANTUÁRIO DE SANTA PAULINA/NOVA TRENTO (SC)

FONTE: GIL, A. H. C. F. (2005)/Acervo Pessoal

Essa espacialidade de expressões conformada pela religião toma sentido específico em representações simbólicas, nas quais os fiéis manifestam gratidão em relação àquilo que é almejado no cotidiano em sua realização espiritual de transcendência própria do ato de peregrinar. As marcas do ato devocional, próprio do imaginário católico, evocam uma resignificação do contato do fiel com o divino na medida em que a permanência do ato de fé é registrado e materializado como graça recebida. (Figura 3)

Assim a espacialidade de expressões retorna como espacialidade de representações própria da linguagem cotidiana e ainda distante do discurso teológico oficial da religião. Trata-se de representações de crenças de conformação mítico-religiosas que emergem no cotidiano e nesse espaço de ação do devir têm a sua mais alta consumação.

Todavia é no templo com o rito exercido pela autoridade eclesiástica que a religiosidade popular é incorporada à territorialidade católica que ao mesmo tempo que acolhe a transforma pela espacialidade do pensamento religioso cujo monopólio a instituição Igreja administra.

\section{CONSIDERAÇÕES FINAIS}

Este ensaio inicial abre possibilidades de uma análise de maior fôlego no futuro. A constituição do Santuário de Santa Paulina, além de suas repercussões óbvias de caráter político e econômico, referenda a própria estrutura em que a forma simbólica de religião conforma a realidade fenomênica da religião.

O espaço de ação, propriamente cultural, das práticas religiosas católicas romanas, no caso do Santuário de Santa Paulina, é também projeção das representações religiosas nas quais a dialeticidade do carisma e intervenção institucional são sintetizados na estrutura do Santuário e sua dinâmica popular.

Desse modo o Santuário não é somente um local sagrado mas parte de uma totalidade estrutural que é o espaço sagrado plasmado pela religião. Como 
GIL, A. H. C. F.; GIL FILHO, S. F. O santuário de Santa Paulina em Nova Trento...

também é na apropriação do carisma que esse espaço representacional é territorializado institucionalmente pela Igreja Romana.

Amabile Lúcia Visintaineré incorporada, sob unção eclesiástica, como Santa Paulina e assim resinificada diante da comunidade dos fiéis. A despeito da geopolítica religiosa que tal processo encerra, existe a devoção sincera do crente na qual Santa Paulina é parte indelével das representações religiosas que edificam o universo de vida do ser religioso em suas práticas cotidianas.

\section{REFERÊNCIAS}

CADORIN, C. B. Serpara os outros - perfil biográfico de madre Paulina do Coração Agonizante de Jesus Amabile Visintainer - 1865-1942. São Paulo: Loyola, 2001.

CONGREGAÇÃO DAS IRMÃZINHAS DA IMACULADA CONCEIÇÃO. Constituições e Diretório. São Paulo: Casa Geral, 1997.
ELIADE, M. O Sagrado e o Profano: A Essência das Religiões. São Paulo: Martins Fontes, 1995.

GHISLANDI, M. A. Entre carisma e Poder: o Território e Territorialidades da Ordem Capuchinha em Curitiba a partir de São Francisco de Assis. Dissertação (Mestrado em Geografia) - Programa de pós-graduação em Geografia, Setor de Ciências da Terra, Universidade Federal do Paraná, Curitiba, 2008.

GIL FILHO, S. F. Geografia da Religião: Reconstruções Teóricas sob o Idealismo Crítico In: KOZEL, S.; SILVA, J. C.; GIL FILHO, S. F. Da Percepção e Cognição à Representação: Reconstruções Teóricas da Geografia Cultural e Humanista. São Paulo: Terceira Margem, 2007.

IGREJA CATÓLICA ROMANA. Catecismo da Igreja Católica. Petrópolis: Editora Vozes, Paulinas, Loyola e Ave-Maria. 1993.

LORENZI, G. Madre Paulina entre carisma e obediência. São Paulo: Edições Loyola, 2001. 